\title{
DIREITO A NACIONALIDADE
}

Jonathan Mayer Araújo Barboza, Shirley Oliveira Lima Nomura

Universidade do Oeste Paulista - UNOESTE, Curso de Direito, Presidente Prudente, SP. E-mail: maverbarboza@hotmail.com

\section{RESUMO}

Este presente trabalho visa demonstrar o direito de nacionalidade. Demonstrando os processos de adquirir a nacionalidade, como brasileiro nato ou por pretensão em mais de uma nacionalidade. 0 presente trabalho foi embasado em bibliografia e efetuado leituras a constituição. Os dados foram examinados com método hipotético dedutivo, isto e, analisadas do geral ao particular.

Palavras - chave: IUS SANGUINIS, IUS SOLI, OPÇÂO

\section{RIGHT TO NATIONALITY}

\section{ABSTRACT}

This paper aims to demonstrate the right to nationality. Demonstrating the processes of acquiring nationality, as born Brazilian or by pretension in more than one nationality. The present work was based on bibliography and made readings of the constitution. The data were examined using a hypothetical deductive method, that is, analyzed from the general to the particular.

Keywords: Ius Sanguinis, Ius Soli, Option 


\section{INTRODUÇÂO}

Visto que, a nacionalidade é adquirida de acordo com o território de origem. De acordo com alguns doutrinadores, veremos a maior relevância argumentada a respeito da nacionalidade e veremos, a tal importância da mesma.

(M.Sylvio,p.451,2018) o povo é um elemento indispensável para a existência do Estado Nacional. Podendo identificar nacionalidade como vinculo politico de natureza jurídica que une o individuo a um Estado.

Veremos com mais detalhes alguns tópicos mais elaborados e com mais informações sobre a tal aquisição da naturalidade ou nacionalidade, alguns doutrinadores apresentados, demonstram com mais facilidade e compreensão o tema embasado.

(A.WEBER.cp14, p. 351,2018) estabelece a devida afirmação.

nacionalidade é o vínculo que se estabelece entre um cidadão e um Estado soberano e cidadania é a participação do indivíduo nos negócios políticos do Estado. Podemos dizer que a nacionalidade é um requisito para a cidadania.

No artigo 12 da Constituição federal de 1988 compreende a fixação da nacionalidade, sendo que de extrema importância seguir todos os princípios oferecidos no presente artigo para que possua a nacionalidade de seu território. Visto que, no artigo citado, apresenta duas diferenças, sendo brasileiros natos e naturalizados. Cada um deles possuem suas diferenças aquisições de direitos e deveres, como de exemplo os cargos que podem adquiri-los. Identifica-se também que, a língua portuguesa é o idioma oficial da Republica Federativa do Brasil.

Em sua obra o autor ( MORAES. A, 2017) relata que a constituição federal manteve as causas de aquisição da nacionalidade feita pela constituição anterior, sendo a originária e a secundária, em regra, "ius soli" E "ius sanguinis", visto que de principal objetivo, este presente trabalho, será embasado aos referentes tópicos de mais importância e que são adotados pela constituição vigente, sendo que, cada país estabelece as regras ou critérios para adquirir a racionalidade dos que nascem sobre seu governo .

Identifica-se que o brasileiro nato tem seus privilégio em território de origem, com permissão em desfrutar das moradias, idioma e cultura. De acordo com (BAHIA.F, 2017) "pode se concluir que Filhos brasileiros ( pai ou mãe) seja nato ou naturalizado, nascido em nosso país, será sempre brasileiro nato. Visto que a nacionalidade é um direito de todo cidadão". Como já visto a regra central da aquisição de nacionalidade se estabelece na "suprema lex" artigo 12, inciso I.

\section{IUS SANGUINIS}

Visto que será nacional todo o aquele descendente de brasileiros (natos ou naturalizados) independentemente do local de nascimento. Visto que, essa critério adotado, identifica-se que, o país de origem, mesmo o naturalizado ou o brasileiro nato, tendo seu descendente em outro território que não seja nacional, basta o registro em repetição brasileira para que possua a dupla nacionalidade, se por ventura o novo país adotar o critério "ius soli"

Constituição Federal, art. 12, "c"

São brasileiros nato, os nascidos no estrangeiro de pai brasileiro ou de mãe brasileira, dede que sejam registrados em repartição brasileira competente ou venham residir na Republica Federativa do Brasil e optem, em qualquer tempo, depois de atingida a maioridade, pela nacionalidade brasileira.

Compreende-se que nem todos países adotam os mesmo critérios de aquisição de nacionalidade, tendo em vista que o Brasil além de tais critérios, também adota por opção confirmativa, sendo um dos principais critérios de aquisição. Como visto a nacionalidade subdivide-se duas espécie sendo, primaria ou originaria e secundária ou adquirida. Para facilitar tal entendimento com complementação ao "ius sanguinis" como visto, aquisição pelo sangue. 
A originária sendo imparcial, basta o nascimento , independente da vontade do indivíduo, salvo o país que adotarem o mesmo critério. Já a secundária pode ser adotada como de exemplo o "ius soli" um indivíduo estrangeiro sem nacionalidade, pelo requisitos previstos em lei, poderá adquirir a nacionalidade por critério da territorialidade. Observe -se uma profunda ponderação ao tal critério.

\section{IUS SOLI}

Direito de solo, no artigo 12 da constituição Federal, apresenta um dos requisitos enquadrados ao ius soli, como de exemplo:

Constituição Federal

artigo 12 , inciso I .

a) Os nascidos na República federativa do Brasil, ainda que de pais estrangeiros, desde que estes não estejam a serviços de seu país (ius soli).

Identifica-se através desse critério adotado que, basta o indivíduo nascer em território brasileiro independente da nacionalidade dos seus pais, adquirem a nacionalidade brasileira e através do registro e cumprindo os princípios necessários.

O território nacional deve ser entendido como as terras delimitadas pelas fronteiras geográficas, com rios, baias, golfos, ilhas, bem como espaço aéreo e mar territorial, formando o território propriamente dito; os navios e aeronaves de guerra brasileiro, onde quer que se encontre; os navios mercantes brasileiros em alto-mar ou de passagem em mar territorial estrangeiro; as aeronaves civis brasileiras em voo sobre o alto-mar ou de passagem sobre as águas territoriais ou espaços aéreos estrangeiros.( MORAES. A, p.370, 2016)

De maneira que, o descendente de pai ou mãe brasileira independentemente do território de seu nascimento, considera-se brasileiro nato. Muito das vezes, por devido ao trânsito de acesso ao registro do filho, acaba deixando de obter a dupla nacionalidade ao filho nascido em território estrangeiro. Devido a isto, o filho dos brasileiros após a adquirir a maioridade, pode por opção voluntária adquirir sua nacionalidade.

\section{OPÇÃO}

Este critério adotado se identifica com a conservação da nacionalidade brasileira primaria, já analisada, nacionalidade prestativa. Visto que esse critério ele tem como base a aquisição da nacionalidade após a maioridade, o pai ou mãe brasileira que não estivessem a serviço do Brasil nascido no estrangeiro, fixa a nacionalidade provisória que seria feita perante a justiça Federal.

O momento da fixação de residência no país constitui o fator gerador da nacionalidade, que fica sujeita a uma condição confirmativa, a opção. Ocorre que, pela inexistência de prazo para essa opção, apesar da aquisição temporária da nacionalidade com a fixação da residência, seus efeitos ficarão suspenso até que haja a referida condição confirmativa. ( MORAES. A, p.373, 2016)

A entender que a nacionalidade é de forma provisória até a aprovação do juiz competente para esse caso, fica o interessado no aguardo da obtenção de sua nacionalidade. De acordo com o supremo tribunal Federal se adquirir uma residência no território nacional antes do nascido estrangeiro, será considerado brasileiro nato, após adquirir a maioridade.

Visto que pode o nascido no estrangeiro que obtém residência no brasil pode adquirir sua nacionalidade após a maioridade civil. Conclui-se que, as normas não estipulam mais prazos para a obtenção, podendo ser de forma suspensiva até que optem pela nacionalidade brasileira, a condição de brasileiro nato fica suspensa, nesse prazo o Brasil reconhece como nacional, mas a manifestação voluntária do Estado não se manifesta até a realização do acontecimento previsto sendo a , Opção. 


\section{CONCLUSÃO}

Verifica-se que, a nacionalidade tem seus conceitos através do povo, população, nação e cidadão. Visto também que, a cultura, território, religião, idioma, tudo se engloba a uma pessoa que representa seus território de origem, visto que nem todos países adotam os mesmos critérios de obtenção de nacionalidade. A República Federativa do Brasil, adota o "ius sanguinis" e"ius soli" verifica-se que os descendentes tem direito de nacionalidade por sangue, por território e por opção. Ocorre também outros meios de aquisição de nacionalidade, como de exemplo o quinzenal, o artigo 12, inciso II, alínea "b" são brasileiros naturalizados os estrangeiros de qualquer nacionalidade, residentes na República federativa do Brasil há mais de quinze anos ininterruptos e sem condenação penal, desde que requeiram a nacionalidade brasileira.

De acordo com o artigo citado, a constituição anterior disponibilizava o prazo de trinta anos ininterruptos, mas a nova constituição adquiriu um prazo mais prévio. Visto todos os princípios apresentados ao artigo 12 da constituição do Brasil, devem o mesmo, respeitados para tornar-se brasileiro nato ou naturalizado. Na mesma linha de pensamento, identifica-se que o brasileiro pode em casos, perder a nacionalidade, como de exemplo, aquele que enfrentar uma ação de cancelamento de naturalização em trânsito julgado, tendo declarado judicialmente a perda da nacionalidade brasileira. Visto várias hipóteses de obtenção e perda da nacionalidade, ocorre pessoas de dupla cidadania, sendo titular de dois Estados ao mesmo tempo.

\section{REFERÊNCIAS}

Motta, Sylvio- Direito Constitucional: Teoria, Jurisprudência e Questões / Sylvio Motta. 27. ed. rev. e atual. - Rio de Janeiro: Forense; São Paulo: MÉTODO, 2018.

Agra, Walber de Moura - Curso de Direito Constitucional / Walber de Moura Agra.- 9. ed. Belo Horizonte : Fórum, 2018.

MORAES, ALEXANDRE DE - Direito Constitucional - 32. ed. revista. Atual, até EC $n^{\circ} 91$, de 18 de Fevereiro de 2016, São Paulo, 2016.

DUTRA, LUCIANO - Direito Constitucional Essencial - 3. ed. revista., atual e ampl - Rio de Janeiro: Forense: São Paulo: MÉTODO 2017. 